\title{
Evasão escolar na graduação em Musicoterapia da Universidade Estadual do Paraná
}

\author{
Lázaro Castro Silva Nascimentoi(i) \\ Universidade Estadual do Paraná, Curitiba, PR, Brasil \\ Sheila Maria Ogasavara Beggiatoii(i) \\ Universidade Estadual do Paraná, Curitiba, PR, Brasil
}

\begin{abstract}
Resumo
O ingresso no ensino superior é uma escolha multifatorial que envolve questões financeiras, sociais, familiares e pessoais. Comumente há uma taxa de evasão de discentes por questões diversas em todo o ensino superior. Este estudo objetiva conhecer as motivações para a evasão na graduação em Musicoterapia na Universidade Estadual do Paraná entre 2013 e 2018. Trata-se de estudo de metodologia mista, com dados de estatística descritiva e dados qualitativos. Após aprovação no Comitê de Ética em Pesquisa, foi realizada coleta on-line com formulários estruturados. Participaram da pesquisa 22 respondentes. As motivações mais frequentes na decisão por abandonar ou trancar o curso referem-se a questões financeiras, à não identificação com a área da Musicoterapia e à dificuldade em desenvolver habilidades e competências musicais. Minimizar a taxa de evasão escolar na graduação em Musicoterapia amplia o número de musicoterapeutas e fortalece socialmente a Musicoterapia como ciência e profissão.
\end{abstract}

Palavras-chave

Musicoterapia. Evasão escolar. Ensino superior.

\section{School evasion in Music Therapy graduation of Paraná State University}

\begin{abstract}
Joining to Higher Education is a multifactorial choice based in financial, social, family and personal reasons. As it is common throughout Higher Education, there is an evasion rate of students for various reasons. This study aims to understand the motivations for evasion in the Bachelor of Music Therapy program at the State University of Paraná from 2013 to 2018. This study used a mixed methodology with descriptive statistics and qualitative data. After approval by the research ethics committee, an online survey was conducted. Twenty-two students participated in the study. The motivations that most influence the decision to abandon the graduation in Music Therapy were related to financial issues, lack of identification with the Music Therapy area and difficulty to develop musical competences. To minimize the rate of college dropout in Music Therapy graduation maximizes the number of Music Therapists strengthening socially the Music Therapy science and profession.
\end{abstract}

\section{Keywords}

Music therapy. School dropout. Higher education. 


\title{
Evasión escolar en la graduación de Musicoterapia de la Universidad del Estado de Paraná
}

\begin{abstract}
Resumen
La entrada a la educación superior es una eleccion multifactorial que involucra problemas financieros, sociales, familiares y personales. Comúnmente hay una tasa de deserción de estudiantes por varias razones a lo largo de la educación superior. Este estudio tiene como objetivo conocer las motivaciones para el abandono de la graduación de Musicoterapia en la Universidad Estatal de Paraná entre 2013 y 2018. Es un estudio de metodología mixta, con estadísticas descriptivas y datos cualitativos. Después de la aprobación del Comité de Ética en Investigación, la recolección online se realizó con formas estructuradas. Participaron en el estudio 22 estudiantes. Las motivaciones más frecuentes en la decisión de abandonar o bloquear el curso se refieren a cuestiones financieras, falta de identificación con el área de la Musicoterapia y dificultad para desarrollar habilidades y competencias musicales. La reducción al mínimo de las tasas de abandono en los estudiantes universitarios de Musicoterapia aumenta el número de musicoterapeutas y fortalece socialmente la Musicoterapia como ciencia y profesión.
\end{abstract}

Palabras clave

Musicoterapia. Abandono escolar. Educación universitaria.

\section{Introdução}

O ingresso em um curso superior é visto como uma busca de crescimento pessoal ou, por vezes, é uma resposta às exigências familiares, segundo Magalhães e Redivo (1998). Os autores afirmam ainda que o desejo de frequentar o nível superior é acompanhado de expectativas de independência, status e facilidade em relação à empregabilidade. Contudo, algumas situações impedem que estudantes concluam 0 curso superior, como a evasão escolar/universitária. Para Bardagi (2007), a evasão escolar no ensino superior é um fenômeno complexo e com diversos aspectos, sendo a insatisfação de estudantes com o curso superior apenas um deles.

Pensando os estudos e políticas acerca da temática da evasão no Brasil, Kipnis (2000) assinala a instituição da "Comissão Especial para o Estudo da Evasão" pela Secretaria de Educação Superior (Sesu) do Ministério da Educação e do Desporto (MEC), em 1995, como marco importante na compreensão desse fenômeno. Naquele mesmo ano, o MEC e as universidades públicas brasileiras manifestaram grande preocupação com o assunto, uma vez que a evasão representava - e ainda

Educ. Form., Fortaleza, v. 5, n. 3, e2080, set./dez. 2020 DOI: https://doi.org/10.25053/redufor.v5i15set/dez.2080 https://revistas.uece.br/index.php/redufor/index ISSN: 2448-3583 
representa - um dado desfavorável às instituições de ensino, tornando-se um tema da agenda governamental.

Em 1996, a Associação Nacional dos Dirigentes de Instituições Federais de Ensino Superior (Andifes), ao discutir questões de diplomação, retenção e evasão no ensino superior brasileiro, nomeou a evasão de três formas distintas:

1) evasão de curso: quando o estudante desliga-se do curso superior em situações diversas, tais como: abandono (deixa de matricular-se), desistência (oficial), transferência ou reopção (mudança de curso), exclusão por norma institucional; 2) evasão da instituição: quando o estudante desliga-se da instituição na qual está matriculado; 3) evasão do sistema: quando o estudante abandona de forma definitiva ou temporária o ensino superior. (ANDIFES, 1996, p. 16, grifo dos autores).

Segundo Bueno (1993), a palavra "evasão" pode significar uma postura ativa da/o aluna/o que decide se desligar por sua própria responsabilidade. Há, sem dúvida, inúmeros fatores, internos e externos, atingindo a questão da sua permanência na universidade. Para esse mesmo autor, o fenômeno da evasão universitária deve ser compreendido como centrado na escolha profissional de jovens, que, por sua vez, é envolvida pelas possibilidades de realização de um projeto pessoal. Dessa forma, a existência da evasão não é, senão, o sinal de que existem alunos insatisfeitos no curso e em seus objetivos pessoais (BUENO, 1993).

A falta de prestígio social de certas profissões reduz o incentivo para que estas sejam buscadas com persistência. $O$ baixo salário e as condições inadequadas de trabalho levam, por exemplo, os cursos de licenciatura e de bacharelado a serem considerados uma atividade secundária. Além disso, as limitadas possibilidades de sucesso financeiro, como empregado ou no magistério, apresentam-se já no início da vida universitária, e logo à primeira dificuldade, estudantes de cursos com essas características, com limitadas chances de emprego e falta de prestígio, de condições de trabalho, de sucesso financeiro e de realização profissional, desistem dos cursos (ADACHI 2009; BUENO, 1993).

Juntamente com a questão da evasão, é necessário minimamente pontuar, no que tange à permanência de discentes na universidade, quanto aos processos de democratização do acesso ao ensino superior. Filipak e Pacheco (2017, p. 1260) refletem sobre isso e afirmam que:

Educ. Form., Fortaleza, v. 5, n. 3, e2080, set./dez. 2020 
Para que ocorra de modo efetivo a democratização da educação superior no Brasil, não é suficiente garantir apenas o acesso gratuito ao estudante; as políticas públicas educacionais devem garantir sua permanência, pois, além da mensalidade, os estudantes possuem despesas com alimentação, transporte, moradia, materiais escolares, livros, fotocópias, impressões, entre outras.

De acordo com os dados do Censo de Ensino Superior (Censup), em 2017, ingressaram em Instituições de Ensino Superior (IES) 3.226.249 estudantes. Contudo, nesse mesmo ano, graduaram-se apenas 947.606, sendo 238.061 (25,12\%) em IES públicas e $709.545(74,88 \%)$ em IES privadas, dado que aponta uma tendência de crescimento de IES privadas (INEP, 2017).

A graduação em Musicoterapia da Universidade Estadual do Paraná (Unespar) foi a primeira ofertada em uma IES pública no Brasil, com início em 1983 e duração de quatro anos. Em sua última reforma curricular, em 2018, o curso de Musicoterapia da Unespar reestruturou seu projeto curricular pedagógico, passando a funcionar com a oferta de 52 disciplinas obrigatórias (2.323 horas), 27 disciplinas optativas (270 horas) e disciplinas eletivas, além de 420 horas de estágio e 180 horas de atividades complementares, somando-se a isso a construção de um Trabalho de Conclusão de Curso (TCC) e a escrita de quatro estudos de caso durante os estágios, totalizando 3.193 horas.

Desde 2015, o curso integra a lista de opções do Sistema de Seleção Unificada (Sisu), ofertando 15 vagas via Exame Nacional do Ensino Médio (Enem/Sisu) e 15 vagas pelo vestibular local da Unespar, com uma entrada anual apenas no primeiro semestre. Um detalhe importante sobre a entrada no Sisu foi a remoção do Teste de Habilidades Específicas (THE), que avaliava competências e habilidades musicais das/dos candidatas/os para o curso de Musicoterapia.

De acordo com o site da Unespar (c2019), o corpo docente do curso é composto por 12 professoras/es, sendo seis destes musicoterapeutas e seis de áreas correlatas, como Educação Física, Fonoaudiologia, Pedagogia, Fisioterapia e Antropologia. A qualificação acadêmica das/os docentes é distribuída entre seis doutoras/es e seis mestras/es, além de possuir atualmente dois docentes contratados em Processo Seletivo Simplificado (PSS) para vagas temporárias.

Em 2019, o Brasil apresenta sete cursos de graduação, dos quais três são em IES privadas e quatro em IES públicas. As instituições públicas, além da Unespar, são a Universidade Federal de Goiás (UFG), a Universidade Federal de Minas Gerais (UFMG)

Educ. Form., Fortaleza, v. 5, n. 3, e2080, set./dez. 2020 
e a Universidade Federal do Rio de Janeiro (UFRJ); já as privadas são o Conservatório Brasileiro de Musicoterapia (Rio de Janeiro/RJ), o Centro Universitário das Faculdades Metropolitanas Unidas (São Paulo/SP) e as Faculdades EST (São Leopoldo/RS).

Com relação às questões de evasão escolar na Unespar, é necessário refletir sobre o baixo número de ingressantes e egressas/os da graduação em Musicoterapia da instituição. Nos anos de 2017 e 2018, a título de exemplificação, houve apenas nove egressas/os, seis destes em 2017 e apenas três em 2018. Vale destacar que tanto a turma de 2017, com ingresso em 2013, quanto a turma de 2018, com ingresso em 2014, possuíam 30 vagas nos processos seletivos de vestibular, mas ainda contavam com 0 THE. Em 2013, ingressaram 19 estudantes e, em 2014, apenas 11 . O cenário mudou positivamente em 2015, com a entrada de 30 discentes, quando da adesão da universidade ao Sisu.

Buscando enfrentar a problemática da evasão, em 2017, foi constituído o Grupo de Trabalho de Acesso, Permanência e Evasão, com objetivo de "[...] discutir temas relativos ao acesso, à permanência e à evasão na Unespar com vistas à proposição de ações que possam melhorar, em alguma medida, a qualidade dos cursos de graduação da universidade" (UNESPAR, 2017a, s.p.). Esse fato demonstra sensibilidade e cuidado da instituição com o tema da evasão universitária.

Diante desse cenário, a pesquisa aqui proposta teve como objetivo conhecer as motivações para a evasão escolar na graduação em Musicoterapia da Unespar, levantando dados estatísticos descritivos e qualitativos acerca da evasão no curso de Musicoterapia.

\section{Caminhos teórico-metodológicos}

Esta pesquisa foi desenvolvida com uma metodologia mista (CRESWELL, 2010), relacionando dados quantitativos, a partir de estatística descritiva com variáveis qualitativas e quantitativas, bem como com dados qualitativos. No que concerne aos dados qualitativos, para Minayo (2009, p. 21), a pesquisa qualitativa "[...] trabalha com o universo dos significados, dos motivos, das aspirações, das crenças, dos valores e das atitudes [...], pois o ser humano se distingue não só por agir, mas por pensar sobre o que faz e por interpretar suas ações". 
Foi realizada uma survey ${ }^{1}$ não probabilística, constituída por julgamento conforme a disponibilidade das/dos participantes. Metodologicamente, segundo Gil (2008), o enquadre deste estudo pode ser também situado como pesquisa exploratória, uma vez que possibilita uma aproximação a uma visão geral da problemática estudada, ampliando sua compreensão para estudos, intervenções ou mesmo políticas de ação posteriores.

Para a análise qualitativa, a leitura e a compreensão dos dados foram orientadas a partir da proposta de Gomes (2009, p. 91), acerca da "análise de conteúdo temática", seguindo os três passos para sua execução: 1) pré-análise, com leitura compreensiva exaustiva a fim de impregnar o pesquisador com os conteúdos do material analisado; 2) exploração do material, em que se distribuem trechos ou frases do material analisado, construindo-se os núcleos de sentido/categorias; e 3) interpretação, etapa final na qual é realizada uma síntese interpretativa relacionando os conteúdos analisados com objetivos e questões propostas.

Neste estudo em questão, não houve nenhuma categoria construída a priori. Todas as categorias foram construídas após a coleta e leitura exaustiva do material coletado; a categorização foi realizada por pares.

\subsection{Coleta de dados e questões éticas}

O material para a coleta de dados foi integralmente virtual, via formulário on-line, contendo perguntas sobre dados sociodemográficos e investigando acerca do fenômeno da evasão juntamente às/aos participantes, com perguntas fechadas e uma pergunta aberta. A fim de garantir as questões éticas da pesquisa, o projeto foi submetido à Plataforma Brasil para a avaliação pelo Comitê de Ética em Pesquisa com Seres Humanos, tendo sido aprovado sob o número CAAE 80784517.1.0000.0094. O formulário on-line possuía em sua primeira página o Termo de Consentimento Livre e Esclarecido (TCLE).

1 Surveys são investigações que colhem dados de amostra representativa de uma população específica, os quais são descritos e analiticamente explicados. Pretende-se que os resultados sejam generalizáveis ao universo dessa população, evitando-se realizar o censo, ou seja, ouvir todos os indivíduos, o que é geralmente impossível, por questão de custo de coleta e tabulação, e visando à melhoria da apresentação dos dados (CENDÓN; RIBEIRO; CHAVES, 2014).

Educ. Form., Fortaleza, v. 5, n. 3, e2080, set./dez. 2020

DOI: https://doi.org/10.25053/redufor.v5i15set/dez.2080

https://revistas.uece.br/index.php/redufor/index 


\subsection{Questionário on-line}

O questionário on-line foi disponibilizado na plataforma Google Forms, possuindo quatro seções distintas. Na primeira, foi apresentado o TCLE, orientando a/o respondente sobre a pesquisa em curso. Na segunda seção, havia o levantamento de dados sociodemográficos, como sexo, ano de nascimento, cidade e estado de origem. A terceira seção versava sobre o período na graduação em Musicoterapia da Unespar, levantando o ano e o meio de ingresso com as alternativas de vestibular tradicional, Enem/Sisu ou ainda se como portadora/portador de diploma, bem como perguntando se a/o respondente havia mudado de cidade para estudar. A quarta e última seção do questionário esteve subdividida em três opções, de forma a facilitar a coleta e análise dos dados. A/O respondente deveria informar a situação de sua matrícula, segundo as ordens: "a) Cancelei minha matrícula"; "b) Abandonei o curso, porém não tranquei minha matrícula"; e "c) Tranquei minha matrícula e estou com ela trancada".

Na sequência, o questionário seguia para a pergunta fechada ("Escolha entre $1 \mathrm{e}$ 3 itens abaixo que mais influenciou(aram) sua decisão de cancelar a matrícula/abandonar o curso/trancar sua matrícula") e uma pergunta aberta ("Há outros fatores que a/o motivaram na decisão de cancelar a matrícula/abandonar o curso/trancar sua matrícula?"). Os itens do formulário foram construídos baseando-se em dois eixos centrais: o primeiro nas pesquisas sobre evasão (BARDAGI, 2007; FILIPAK; PACHECO, 2017) e o segundo em indagações comuns aos pesquisadores, a partir da experiência da coautora do estudo.

\subsection{População e critérios de amostragem}

A população da pesquisa foi constituída por discentes em situação de matrícula trancada, com matrícula cancelada ou que haviam abandonado o curso, todas/os da graduação em Musicoterapia da Unespar, tendo sido composta por 26 respondentes que participaram via formulário on-line no período de 27 de agosto a 21 de outubro de 2018. Para constituir a amostra, foram solicitados ao corpo discente do curso, aos musicoterapeutas egressas/os da rede de contato dos pesquisadores e à coordenadora

Educ. Form., Fortaleza, v. 5, n. 3, e2080, set./dez. 2020 DOI: https://doi.org/10.25053/redufor.v5i15set/dez.2080 https://revistas.uece.br/index.php/redufor/index 
do curso de Musicoterapia os contatos (e-mail e telefone) de estudantes que se encaixassem nos critérios da amostra.

Os critérios para a inclusão na amostra foram: 1) ter ingressado na graduação em Musicoterapia entre 2013 e 2018; 2) estar com a matrícula trancada no período entre agosto e outubro de 2018, período da coleta de dados on-line, ou ter matrícula com o status de cancelada; e 3) ter disponibilidade para responder ao formulário on-line. Já os critérios de exclusão adotados foram: 1) ter ingressado antes de 2013 na graduação de Musicoterapia; 2) estar com matrícula ativa no curso; e 3) ter concluído a graduação em Musicoterapia.

\section{Resultados e discussão}

Dos 26 respondentes do formulário, quatro foram excluídos por não se encaixarem no período levantado (ingresso entre 2013 e 2018), sendo, portanto, 22 $(n=22)$ o total de participantes válidos desta pesquisa.

\subsection{Dados sociodemográficos}

No que compete à distribuição da amostra por sexo, os dados (Gráfico 1) coadunam-se com os apresentados pelo Instituto Nacional de Estudos e Pesquisas Educacionais Anísio Teixeira (2017), informando que há maior entrada de mulheres na universidade do que de homens. Apesar de se tratar de estudantes que se evadiram do curso, estes dados também caminham na direção do que é conhecido dentro da musicoterapia brasileira: a profissão de musicoterapeuta é majoritariamente desenvolvida por mulheres, havendo mais estudantes do sexo feminino nos cursos de formação em Musicoterapia no geral.

De acordo com Godoy (2014), os primórdios da Musicoterapia no Brasil estiveram intimamente ligados a mulheres, dados que dialogam com os apresentados por Matos, Toassi e Oliveira (2013), que investigaram sobre o processo de feminização nas profissões de saúde no Brasil, mesmo que as autoras não mencionem a Musicoterapia. 
Gráfico 1 - Dados sociodemográficos: distribuição da amostra por sexo

\section{Sexo}

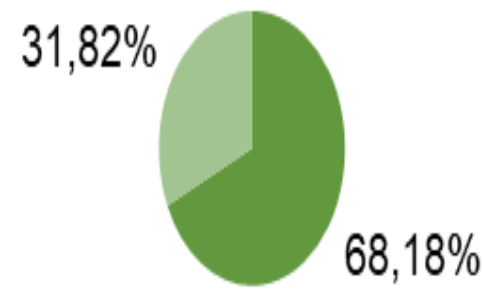

-Feminino

Masculino

Fonte: Nascimento (2018, p. 9).

Os anos de nascimento das/dos respondentes (Gráfico 2) mostram uma larga faixa etária entre aquelas/es que se evadiram da graduação em Musicoterapia da Unespar. As/Os respondentes apresentavam idades entre 18 e 61 anos, dados que também dialogam com as faixas etárias presentes no corpo discente do curso e turmas com bastante diversidade etária.

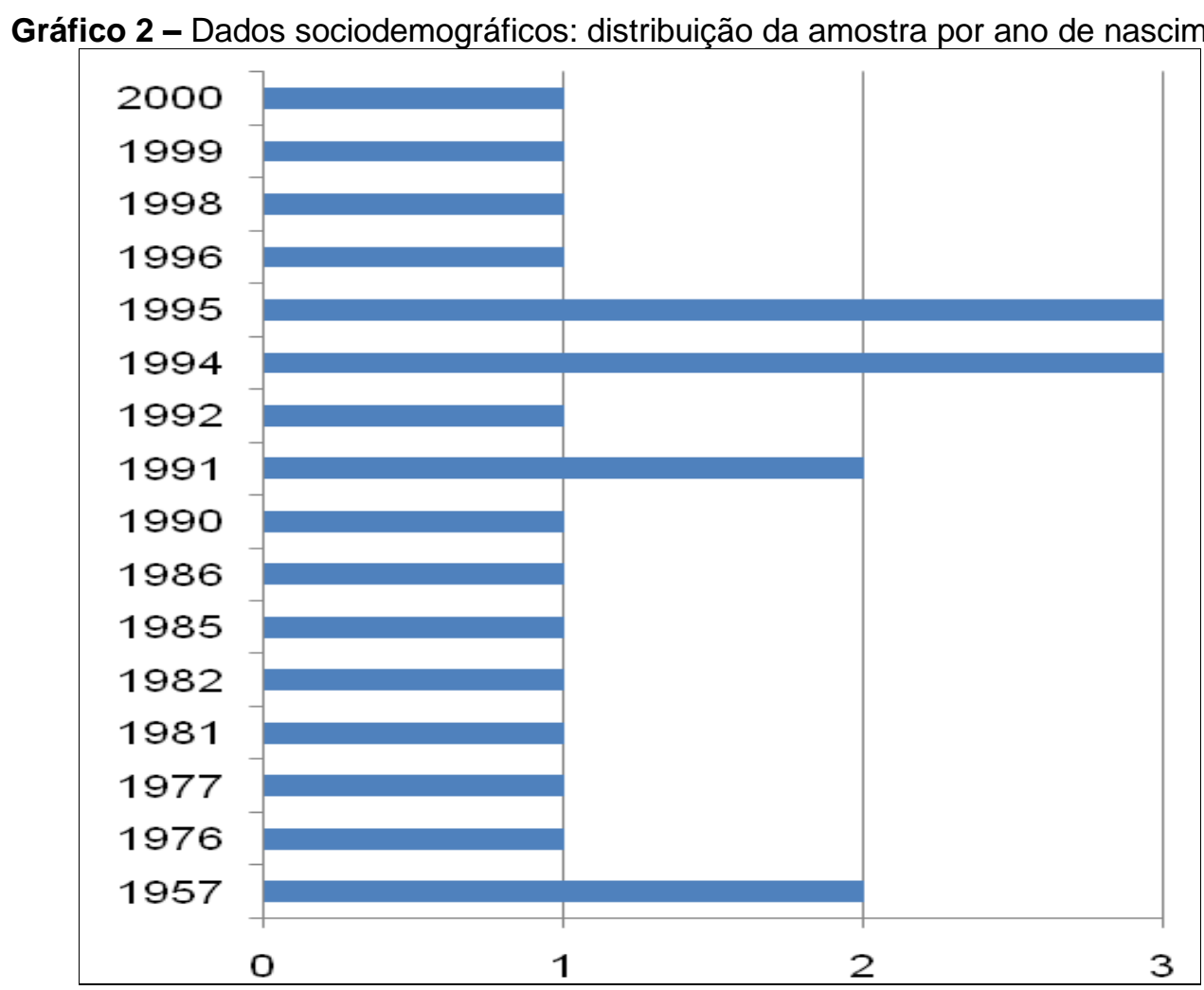

Fonte: Nascimento (2018, p. 10).

Educ. Form., Fortaleza, v. 5, n. 3, e2080, set./dez. 2020

DOI: https://doi.org/10.25053/redufor.v5i15set/dez.2080

https://revistas.uece.br/index.php/redufor/index 
Ainda sobre o aspecto etário das/dos respondentes, é possível indagar se a graduação em Musicoterapia teria sido suas primeiras escolhas profissionais em nível de formação universitária ou uma escolha secundária para aquelas/es que já possuíam outras formações.

\subsection{Dados a respeito do vínculo com a Unespar}

A distribuição das/dos respondentes pertinente ao ingresso na Unespar também foi diversa (Gráfico 3). Distribuíram-se em 45,45\% com entrada via vestibular local, $31,82 \%$ com entrada pelo Enem/Sisu e 22,73\% com aproveitamento de estudos para portadoras/es de diplomas do ensino superior.

Gráfico 3 - Distribuição da amostra por meio de ingresso

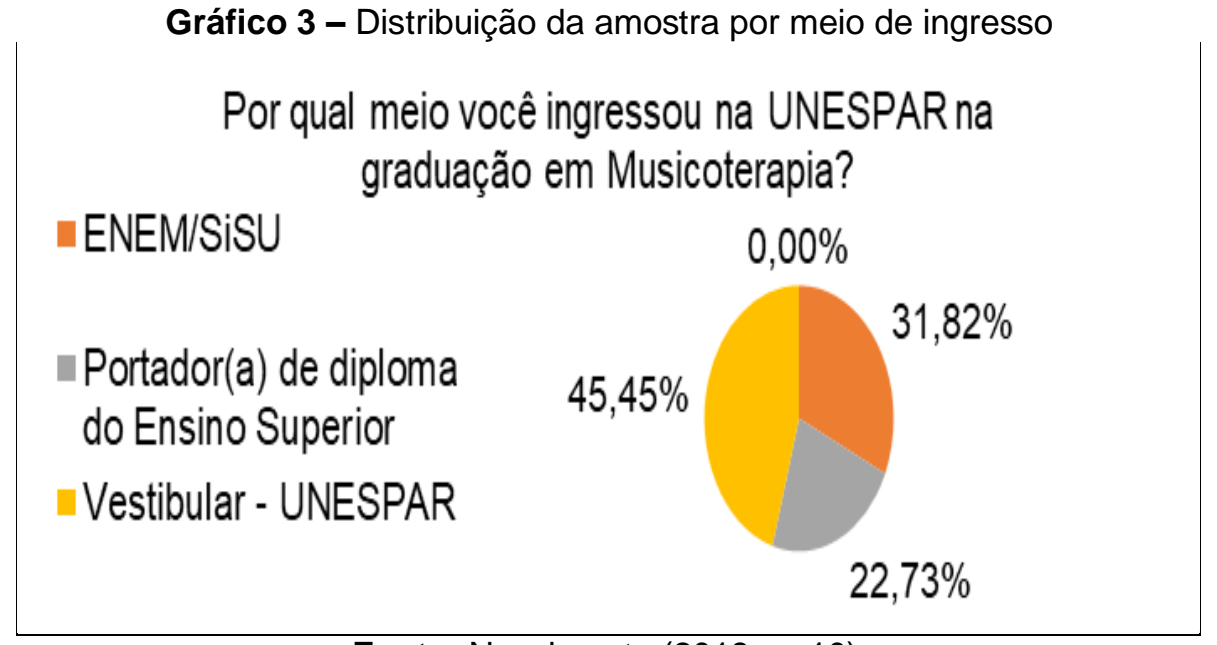

Fonte: Nascimento (2018, p. 10).

Quanto ao ano de ingresso no curso (Gráfico 4), a amostra distribuiu-se com concentração nos anos de 2016, com oito respondentes; 2015, com cinco respondentes; e 2017, com quatro respondentes. Os anos de 2014 e 2018 tiveram apenas um respondente cada e o ano de 2013, três respondentes.

Outro detalhe que auxilia na compreensão dessa distribuição diz respeito às entradas no curso. Como já mencionado, em 2014, houve apenas 11 estudantes aptas/os para ingresso no curso após processo seletivo, ao passo que, de 2015 em diante, com a inclusão do curso no Enem/Sisu, as turmas passaram a ter um quantitativo de 30 ou mais discentes por ano.

Educ. Form., Fortaleza, v. 5, n. 3, e2080, set./dez. 2020 


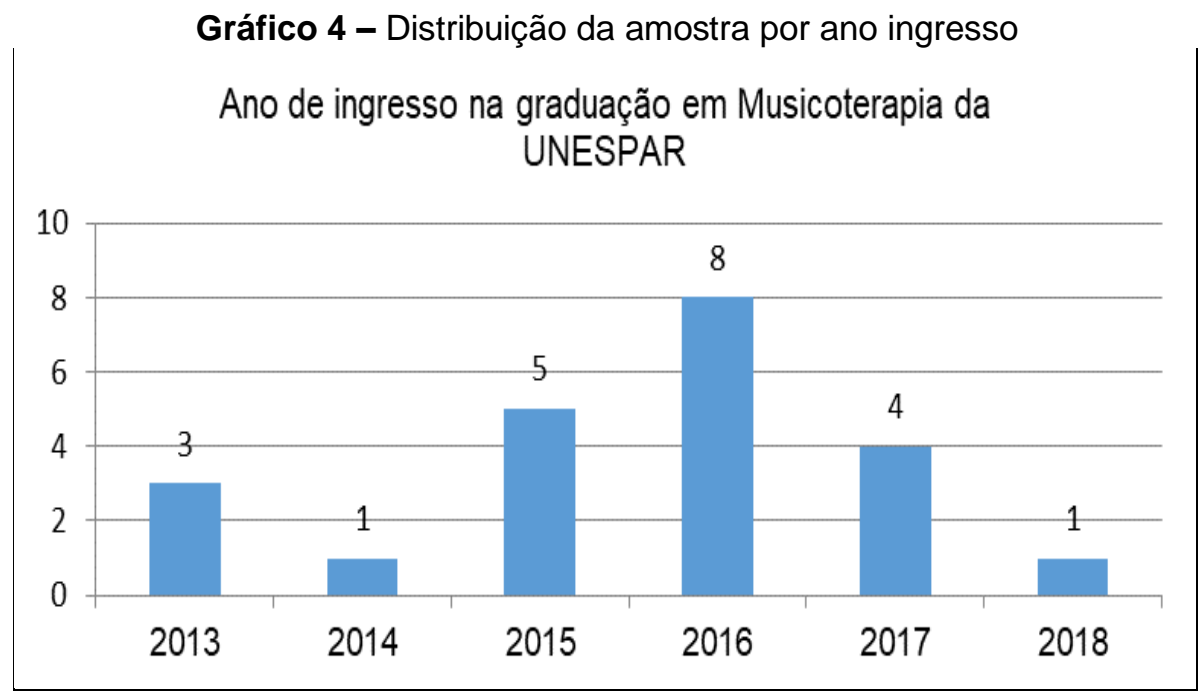

Fonte: Nascimento (2018, p. 11).

Existem apenas sete cursos ativos em nível de graduação em Musicoterapia no Brasil, com concentração nas regiões Sudeste, Sul e Centro-Oeste. Isso faz com que seja comum a mudança de cidade para o ingresso no curso. Contudo, as/os respondentes informaram que, em sua maioria (63,64\%), não tiveram que mudar de cidade para realizá-lo (Gráfico 5). Vale refletir como a graduação de Musicoterapia promove uma espacialização geográfica, considerando a necessidade de mudança de cidade para a realização do curso por parte do corpo discente.

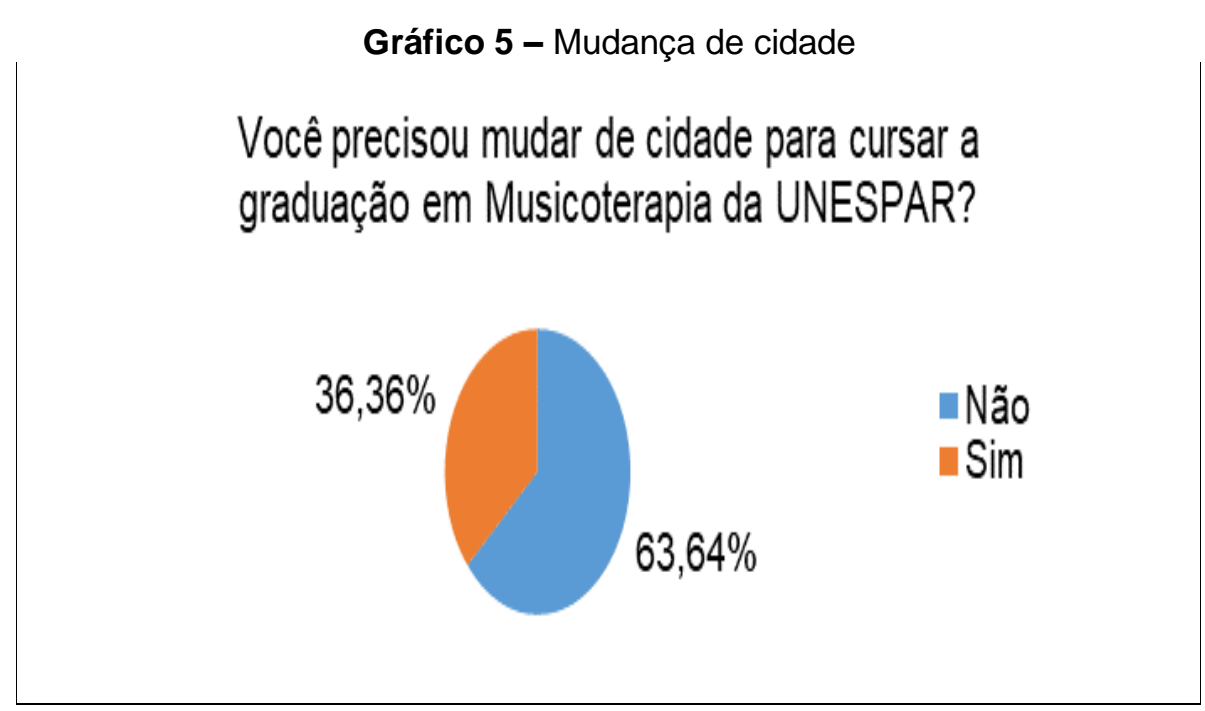

Fonte: Nascimento (2018, p. 11).

A situação de matrícula no curso (Gráfico 6) aponta que a maioria das/dos respondentes $(68,18 \%)$ abandonou o curso sem realizar o trancamento ou 0 
cancelamento de matrícula. Esta certamente é uma temática sensível que merece atenção. Apesar de o Brasil ser reconhecido pelo excesso de trâmites burocráticos, tanto na esfera pública quanto na privada, a ação de abandonar o curso sem trancamento de matrícula ou cancelamento desta impacta diretamente o quadro de vagas ofertadas pela instituição para portadoras/es de diplomas.

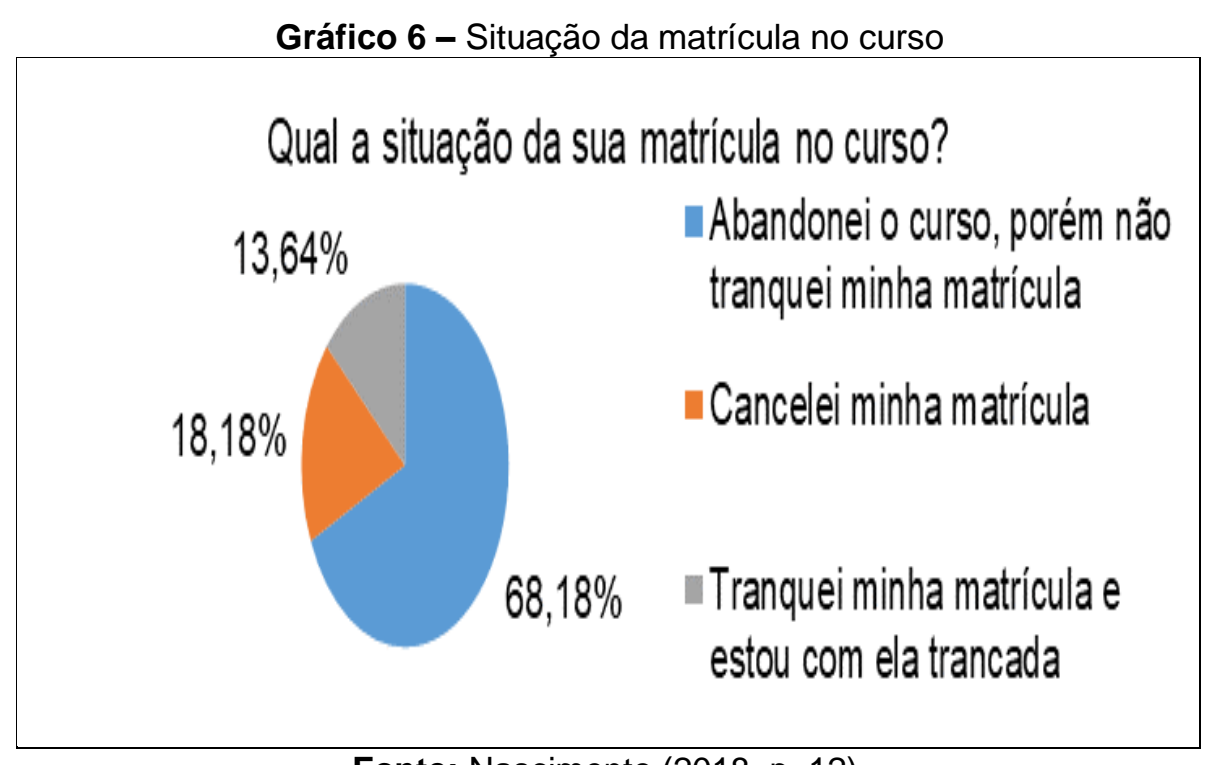

Fonte: Nascimento (2018, p. 12).

Na sequência, encontram-se as motivações para a evasão na graduação em Musicoterapia. Os dados serão apresentados em dois grupos, o primeiro com as respostas à questão fechada do formulário on-line e o segundo, com a categorização temática das respostas à questão aberta.

\subsection{Motivações para a evasão na graduação em Musicoterapia}

A questão fechada que investigava acerca das motivações para a evasão do curso de Musicoterapia possuía 14 itens, em que cada respondente poderia escolher entre uma e três opções para justificar os motivos para sua desistência do curso. 


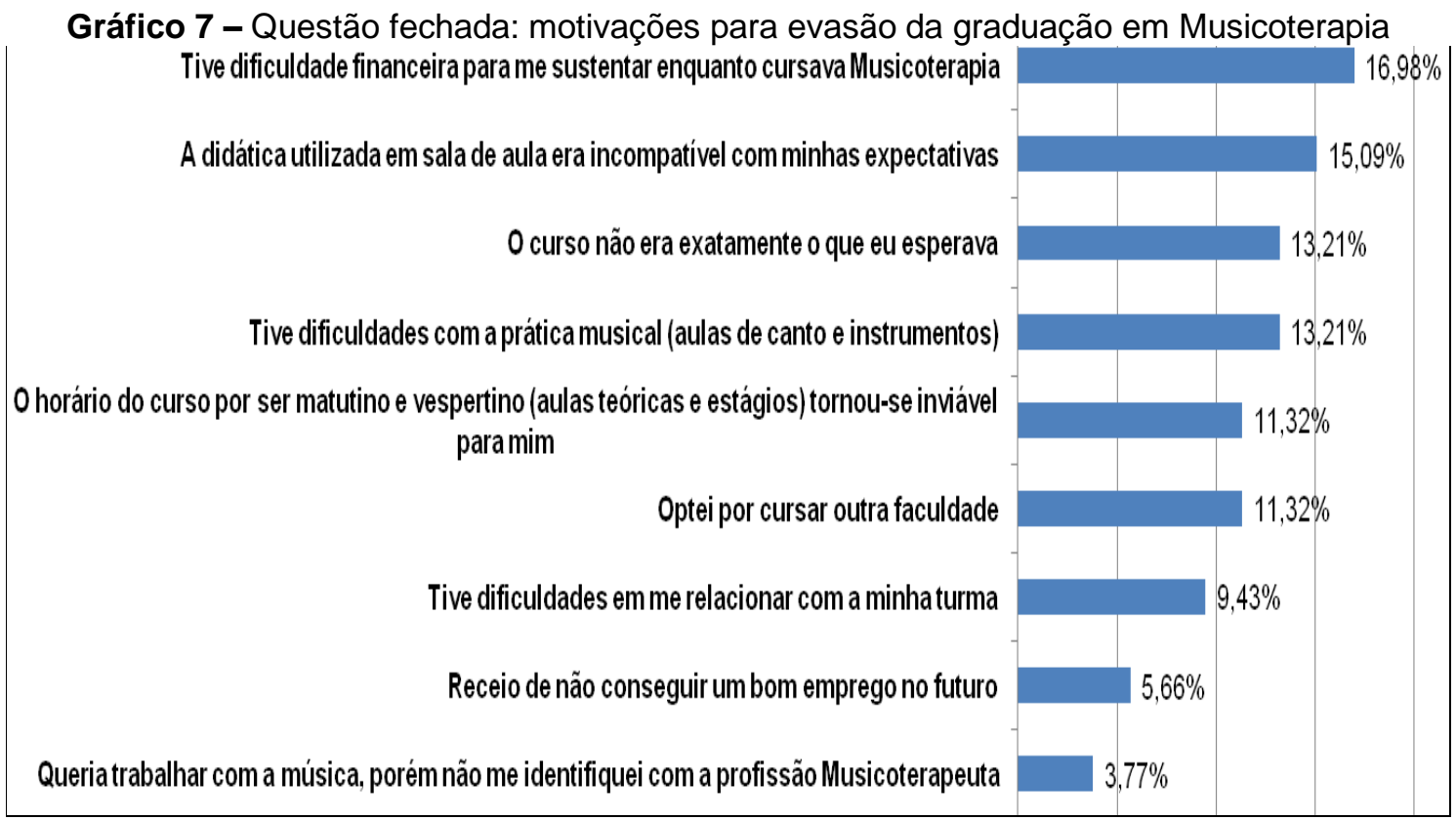

Fonte: Nascimento (2018, p. 13).

A opção "Tive dificuldade financeira para me sustentar enquanto cursava Musicoterapia" figurou como o principal motivo para a desistência do curso, com 16,98\% das respostas. Infelizmente essa é uma realidade comum em território brasileiro, considerando-se o alto nível de desigualdade socioeconômica vivida por brasileiras/os. A manutenção de uma/um estudante no ensino superior, mesmo que em uma instituição de ensino pública e gratuita, não a/o isenta de custos como moradia, alimentação, saúde, cultura, lazer e afins.

As políticas de permanência oferecidas pela Unespar ainda são frágeis. Dados de 2015, no site da Unespar, informavam que a instituição possuía 10.445 discentes matriculadas/os. O seu programa de bolsa permanência, porém, oferta apenas 21 bolsas, divididas entre seus sete campi em funcionamento até o presente momento, de acordo com o Edital nº 01/2017 - Programa Institucional de Bolsas Permanência (UNESPAR, 2017b).

Além da fragilidade com os programas de bolsa permanência, vale mencionar que os campi Curitiba I e Curitiba II, sendo neste último onde está alocada a graduação em Musicoterapia, ainda não possuem a política de Restaurantes Universitários (RU), fato que afeta as questões financeiras experimentadas por seu corpo discente.

Como segunda motivação mais expressiva para a desistência do curso, o questionário apresentou a opção "A didática utilizada em sala de aula era incompatível com minhas expectativas", com 15,09\% das respostas. Esse dado aponta para uma crítica

Educ. Form., Fortaleza, v. 5, n. 3, e2080, set./dez. 2020

DOI: https://doi.org/10.25053/redufor.v5i15set/dez.2080

https://revistas.uece.br/index.php/redufor/index 
das/dos respondentes às metodologias de ensino utilizadas em sala de aula pelo corpo docente do curso. No geral, as aulas ofertadas no curso dividem-se entre conteúdos teóricos, vivenciais/experienciais e práticos. Volpi (2006, p. 40) aponta sobre esta questão:

\begin{abstract}
Alguns dos professores que hoje atuam nos cursos de musicoterapia não tiveram formação pedagógica durante a graduação. Isso porque na grade curricular não existem disciplinas que enfoquem a formação do docente em Musicoterapia. Também é nulo qualquer outro tipo de formação didático-pedagógica para preparar musicoterapeutas para a docência, seja em cursos de extensão, de atualização, seja de pós-graduação.
\end{abstract}

A terceira motivação mais expressiva apresentou duas alternativas empatadas: "O curso não era exatamente o que eu esperava" e "Tive dificuldades com a prática musical (aulas de canto e instrumentos)", ambas com 13,21\% das respostas. A primeira delas esbarra em uma questão sensível à Musicoterapia no que diz respeito à identidade da/o profissional musicoterapeuta e da Musicoterapia como ciência. Apesar dos quase 50 anos da área no Brasil, não é incomum encontrar discentes que optaram pelo curso apenas pelo seu nome, sem aprofundamento em leituras sobre a profissão ou sobre a área. $\mathrm{O}$ desconhecimento da área impacta diretamente o imaginário sobre o que faz esse profissional e como está estruturada sua formação, resultando em evasão do curso.

A formação em Musicoterapia exige de suas/seus formandas/os habilidades e competências musicais. Com a entrada do curso da Unespar no Enem/Sisu em 2015, foi retirado da seleção o THE para música. Assim, o currículo passou por uma reforma para que as disciplinas de conteúdo estritamente musical estivessem dispostas durante todo o curso, porém com ênfase em seus quatro primeiros semestres. O desenvolvimento de habilidades e competências musicais pode ser bastante exaustivo tanto para estudantes que não tiveram estudos formais na área previamente à entrada no curso quanto para aquelas/es que já o tiveram.

Como quarta motivação para a evasão, com 11,32\% das respostas, figuraram as opções "O horário do curso por ser matutino e vespertino (aulas teóricas e estágios) tornou-se inviável para mim" e "Optei por cursar outra faculdade". No que tange ao aspecto dos horários, cursos que são ofertados integralmente em um só turno tendem a facilitar que seu corpo discente possa trabalhar ou se vincular a outros projetos que lhe provenham sustento financeiro. A graduação em Musicoterapia da Unespar, contudo, possui componentes curriculares matutinos (aulas teóricas e práticas) e componentes 
que ocorrem em contraturno (no período da tarde), como as 420 horas de estágio curricular supervisionado obrigatório.

Como quinta motivação, com 9,43\% das respostas, figurou a opção "Tive dificuldades em me relacionar com a minha turma". A opção "Receio de não conseguir um bom emprego no futuro" figurou em sexto lugar, com 5,66\% das respostas. E a opção "Queria trabalhar com música, porém não me identifiquei com a profissão musicoterapeuta", em sétimo lugar, com 3,77\% das respostas. As outras cinco opções ${ }^{2}$ disponíveis nessa questão não figuraram como resposta para as/os respondentes.

\subsection{Outros fatores para a evasão na graduação em Musicoterapia}

Para além das motivações apresentadas, o formulário on-line possuía a pergunta aberta: "Há outros fatores que a/o motivaram na decisão de cancelar a matrícula/ abandonar o curso/trancar sua matrícula?", que visava criar um espaço extra para que as/os respondentes pudessem se expressar acerca da motivação para a desistência do curso, não sendo uma pergunta obrigatória.

Do total de 19 respondentes, quatro preencheram à questão apenas com "não", enquanto os outros 15 responderam à pergunta com mais informações. No Quadro 1, apresenta-se uma categorização a partir das orientações de Gomes (2009) para a análise de conteúdo temática. Após a categorização, foram encontradas dez temáticas que motivaram a evasão na graduação em Musicoterapia da Unespar.

\section{Quadro 1 - Categorização temática das respostas à questão aberta}

(continua)

\begin{tabular}{|l|l|}
\hline $\begin{array}{l}\text { T1 - Questões financeiras e do } \\
\text { mercado de trabalho }\end{array}$ & $\begin{array}{l}\text { Receio sobre colocação no mercado de trabalho e } \\
\text { remuneração. }\end{array}$ \\
\hline T2 - Saúde mental & Questões de saúde mental para a evasão do curso. \\
\hline T3 - Habilidade/Conhecimento musical & $\begin{array}{l}\text { Dificuldades no que tange às habilidades e ao conhecimento } \\
\text { musical. }\end{array}$ \\
\hline $\begin{array}{l}\text { T4 - Questões referentes ao processo } \\
\text { seletivo }\end{array}$ & $\begin{array}{l}\text { Forma de ingresso no curso, destacando-se a ausência de } \\
\text { THE na seleção. }\end{array}$ \\
\hline T5 - Relacionamento com a turma & $\begin{array}{l}\text { Respondentes relataram questões interpessoais na relação } \\
\text { com colegas de turma. }\end{array}$ \\
\hline
\end{tabular}

${ }^{2}$ As opções eram: "Falta de acessibilidade para pessoas com deficiência"; "Tive dificuldades com os conteúdos teóricos"; "Tive dificuldades em me relacionar com o corpo docente"; "Baixo desempenho nas avaliações e atividades"; e "Minha família desaprovava o curso".

Educ. Form., Fortaleza, v. 5, n. 3, e2080, set./dez. 2020

DOI: https://doi.org/10.25053/redufor.v5i15set/dez.2080

https://revistas.uece.br/index.php/redufor/index 
Quadro 1 - Categorização temática das respostas à questão aberta

(conclusão)

\begin{tabular}{|l|l|}
\hline $\begin{array}{l}\text { T6 - Corpo docente e estrutura da } \\
\text { instituição pública }\end{array}$ & $\begin{array}{l}\text { Questões ligadas à relação com o corpo docente e à } \\
\text { infraestrutura da instituição de ensino. }\end{array}$ \\
\hline T7 - Estrutura curricular & $\begin{array}{l}\text { Organização das disciplinas e conteúdos curriculares como } \\
\text { motivo para a evasão do curso. }\end{array}$ \\
\hline T8 - Maternidade e universidade & $\begin{array}{l}\text { Questões ligadas à maternidade e à universidade como fator } \\
\text { de desistência do curso. }\end{array}$ \\
\hline T9 - Graduação x Especialização & $\begin{array}{l}\text { Respondentes apresentaram questões referentes à formação } \\
\text { em Musicoterapia nos níveis: graduação e pós-graduação. }\end{array}$ \\
\hline T10 - Outros & Outras temáticas que não se encaixaram nas anteriores. \\
\hline
\end{tabular}

Fonte: Nascimento (2018, p. 17).

Algumas das categorias temáticas que emergiram após a leitura da questão aberta já haviam sido contempladas nas motivações anteriores, por exemplo, as categorias T1 (Questões financeiras e do mercado de trabalho), T3 (Habilidade/ Conhecimento musical), T4 (Questões referentes ao processo seletivo), T5 (Relacionamento com a turma) e T7 (Estrutura curricular).

Com isso, para este trabalho, os autores optaram didaticamente em discutir e aprofundar as outras categorias temáticas, apesar de destacarem que o fato de essas questões figurarem tanto na parte objetiva quanto subjetiva do formulário enfatiza o quanto foram motivações fortes para as/os respondentes desistirem do curso.

$\mathrm{Na}$ categoria temática T2, apresentaram-se como motivações para a desistência do curso questões ligadas à saúde mental das/dos respondentes. Nas respostas, as/os respondentes destacaram quadros clínicos significativos por elas/eles vividos como motivação para o abandono do curso, a saber: depressão, ansiedade, síndrome do pânico, além de questões de saúde familiar. Refletir sobre a saúde do corpo discente é também papel das IES, apresentando políticas de assistência estudantil. Isso se mostra cada vez mais imperativo, haja vista 0 aumento significativo de estudantes universitárias/os que cometem suicídio.

A categoria temática T6 apresenta a relação com o corpo docente e com a estrutura da instituição pública como motivações para a evasão do curso. Nas falas, as/os respondentes indicavam entraves delicados na relação ensino-aprendizagem, sendo possível perceber uma indicação de inabilidade metodológica para o trabalho com estudantes que não tenham vivência anterior formal com a música e seus diversos elementos. Nas palavras de Freire, P., Freire, A. e Oliveira (2016, p. 30): “[...] O fato de que o professor supostamente sabe e que o estudante supostamente não sabe não 
impede o professor de aprender durante o processo de ensinar e o estudante de ensinar no processo de aprender [...]. Esta é a essência da educação democrática".

Nas respostas desta categoria temática também foram mencionadas questões político-sociais da educação pública, como os recorrentes cortes presentes na educação e a precarização do ensino superior de uma forma geral, sendo essa uma pauta de luta permanente a todos os grupos envolvidos no serviço público da instituição, sejam discentes, docentes ou agentes universitários.

$\mathrm{Na}$ categoria temática T8 foi inserida a motivação das relações entre maternidade e universidade. As respostas relatavam dificuldade com a instituição pertinentes às questões ligadas à maternidade, sendo destacado também o fator de dificuldade de relacionamento interpessoal com colegas da mesma turma.

A última categoria temática discutida neste tópico é a T9, que se refere às questões entre o treinamento de musicoterapeutas em nível de graduação e em nível de pós-graduação lato sensu (especialização). A/O respondente informava que, em uma única aula da pós-graduação, havia aprendido mais do que em um ano de graduação em Musicoterapia.

Mesmo já estando na Classificação Brasileira de Ocupações sob o número 2265-05, sendo reconhecida como profissão com ensino superior, a Musicoterapia ainda carece de regulamentação no Brasil. No atual cenário, é possível tornar-se musicoterapeuta tanto via graduação (com cursos de bacharelado) quanto via pós-graduação lato sensu (com especialização).

\section{Considerações finais}

Este estudo apontou as principais motivações para a evasão escolar na graduação em Musicoterapia da Unespar. A dificuldade financeira das/os respondentes apareceu como principal motivação para abandonar/trancar/desistir do curso. Ainda assim, é importante compreender a complexidade que envolve o tema da evasão universitária como um evento multideterminado. Observar esses dados contribui para fortalecer as políticas de permanência no curso de graduação em Musicoterapia.

Refletir acerca das motivações para a evasão na graduação em Musicoterapia é uma temática importante. Os dados desta pesquisa mostram a especificidade que é 
própria da Musicoterapia como área interdisciplinar. Como afirma Godoy (2015, p. 28), "[...] o Musicoterapeuta não se enquadra na categoria de médico, nem músico, nem psicólogo, ele é um profissional diferente com o saber de um conhecimento terapêutico singular", o que convoca a todas/os nós que estamos nesta área a um olhar sensível para suas questões.

O fortalecimento do curso de graduação e da/o profissional musicoterapeuta perpassa por sua formação. O baixo índice de egressas/os no curso de Musicoterapia gera alguns impactos; dentre eles, é possível mencionar que esse número fragiliza 0 argumento favorável à manutenção do curso frente à instituição, ao Estado e a órgãos de fomento diversos, bem como diminui a oferta de profissionais musicoterapeutas devidamente titulados para a atuação no mercado de trabalho, correndo o risco de fragilizar a profissão de maneira global.

Vale ainda mencionar brevemente a importância de reforçar, na era do tecnicismo e das especificidades, uma formação de qualidade em nível de graduação em Musicoterapia. De acordo com Arruda (2014), as graduações em Musicoterapia no Brasil possuem uma média de 2.734 horas, diferenciando-se sensivelmente da carga horária mínima de 360 horas exigidas para cursos em nível de especialização. Além disso, o desenvolvimento da Musicoterapia como ciência e profissão requer esforços coletivos de todas/os aquelas/es que a estudam e a praticam, isso inclui também uma reflexão profunda sobre o fenômeno de evasão universitária existente na área.

\section{Referências}

ADACHI, A. M. C. T. Evasão e evadidos nos cursos de graduação da Universidade Federal de Minas Gerais. 2009. 214 f. Dissertação (Mestrado em Educação) - Programa de Pós-Graduação em Educação, Universidade Federal de Minas Gerais, Belo Horizonte, 2009.

ANDIFES - Associação Nacional dos Dirigentes de Instituições Federais de Ensino Superior. Comissão Especial de Estudos sobre a Evasão nas Universidades Públicas Brasileiras. Diplomação, retenção e evasão nos cursos de graduação em instituições de ensino superior públicas. [S. I.]: Andifes/Abruem/SESu/MEC, 1996. Disponível em: http://www.andifes.org.br/wpcontent/files_flutter/diplomacao_retencao_evasao_graduacao_em_ies_publicas1996.pdf. Acesso em: 1 nov. 2019.

Educ. Form., Fortaleza, v. 5, n. 3, e2080, set./dez. 2020 DOI: https://doi.org/10.25053/redufor.v5i15set/dez.2080 https://revistas.uece.br/index.php/redufor/index 
ARRUDA, M. L. Estudo comparado e a música no currículo dos bacharelados em Musicoterapia do Brasil. In: DREHER, S. F.; MAYER, G. C. T. (Org.). A clínica em Musicoterapia: avanços e perspectivas. São Leopoldo: EST, 2014. p. 291-296.

BARDAGI, M. P. Evasão e comportamento vocacional de universitários: estudos sobre o desenvolvimento de carreira na graduação. 2007. 241 f. Tese (Doutorado em Psicologia) - Programa de Pós-Graduação em Psicologia, Universidade Federal do Rio Grande do Sul, Porto Alegre, 2007.

BUENO, J. L. O. A evasão de alunos. Paidéia, Ribeirão Preto, n. 5, p. 9-16, 1993.

Disponível em: http://www.scielo.br/pdf/paideia/n5/02.pdf. Acesso em: 1ํnov. 2019.

CENDÓN, B. V.; RIBEIRO, N. A.; CHAVES, C. J. Pesquisas de survey: análise das reações dos respondentes. Informação \& Sociedade: Estudos, João Pessoa, v. 24, n. 3, p. 29-48, 2014. Disponível em: https://periodicos.ufpb.br/ojs/index.php/ies/article/view/19963. Acesso em: 1ํnov. 2019.

CRESWELL, J. W. Projeto de pesquisa: métodos qualitativo, quantitativo e misto. Porto Alegre: Artmed: Bookman, 2010.

FILIPAK, S. T.; PACHECO, E. F. H. A democratização do acesso à educação superior no Brasil. Revista Diálogo Educacional, Curitiba, v. 17, n. 54, p. 1241-1268, 2017. Disponível em: https://periodicos.pucpr.br/index.php/dialogoeducacional/article/view/21946. Acesso em: 1 - nov. 2019.

FREIRE, P.; FREIRE, A. M. A.; OLIVEIRA, W. F. Pedagogia da solidariedade. 2. ed. São Paulo: Paz e Terra, 2016.

GIL, A. C. Como elaborar projetos de pesquisa. 4. ed. São Paulo: Atlas, 2008.

GODOY, D. A. Além do musicoterapeuta: um estudo sobre a identidade do musicoterapeuta e seu reconhecimento, fundamentado no sintagma identidademetamorfose-emancipação. 2015. 157 f. Dissertação (Mestrado em Psicologia) Programa de Pós-Graduação em Musicoterapia, Pontifícia Universidade Católica de São Paulo, São Paulo, 2015.

GODOY, D. A. Musicoterapia, profissão e reconhecimento: uma questão de identidade, no contexto social brasileiro. Revista Brasileira de Musicoterapia, São Paulo, v. 16, n. 16, 2014. Disponível em: http://www.revistademusicoterapia.mus.br/wpcontent/uploads/2016/10/1-musicoterapia-profiss\%c3\%83o-e-reconhecimento-umaquest\%c3\%83o-de-identidade-no-contexto-social-brasileiro.pdf. Acesso em: 20 abr. 2020.

GOMES, R. Análise e interpretação de dados de pesquisa qualitativa. In: MINAYO, M. C. S.; DESLANDES, S. F.; GOMES, R. (Org.). Pesquisa social: teoria, método e criatividade. 28. ed. Petrópolis: Vozes, 2009. p. 79-108.

INEP - Instituto Nacional de Estudos e Pesquisas Educacionais Anísio Teixeira. Sinopse Estatística da Educação Superior 2017. Brasília, DF: Inep, 2017. Disponível em: 
http://portal.inep.gov.br/web/guest/sinopses-estatisticas-da-educacao-superior. Acesso em: 1ํㅡov. 2019.

KIPNIS, B. A pesquisa institucional e a educação superior brasileira: um estudo de caso longitudinal da evasão. Linhas Críticas, Brasília, DF, v. 6, n. 11, p. 109-130, 2000.

Disponível em: https://periodicos.unb.br/index.php/linhascriticas/article/view/2870/2574. Acesso em: 20 abr. 2020.

MAGALHÃES, M. O.; REDIVO, A. Re-opção de curso e maturidade vocacional. Revista da $A B O P$, Porto Alegre, v. 2, n. 2, p. 7-28, 1998. Disponível em:

http://pepsic.bvsalud.org/scielo.php?script=sci_arttext\&pid=s1414-88891998000200002. Acesso em: 20 abr. 2020.

MATOS, I. B.; TOASSI, R. F. C.; OLIVEIRA, M. C. Profissões e ocupações de saúde e o processo de feminização: tendências e implicações. Athenea Digital: Revista de

Pensamiento y Investigación Social, Barcelona, v. 13, n. 2, p. 239-244, 2013. Disponível em: https://www.lume.ufrgs.br/bitstream/handle/10183/118035/000894801.pdf?sequence=1.

Acesso em: 20 abr. 2020.

MINAYO, M. C. S. O desafio da pesquisa social. In: MINAYO, M. C. S.; DESLANDES, S. F.; GOMES, R. (Org.). Pesquisa social: teoria, método e criatividade. 28. ed. Petrópolis: Vozes, 2009. p. 9-29.

NASCIMENTO, L. C. S. Evasão escolar no bacharelado em Musicoterapia da Universidade Estadual do Paraná. 2018. Trabalho de Conclusão de Curso (Graduação em Musicoterapia) - Programa de Graduação em Musicoterapia, Universidade Estadual do Paraná, Curitiba, 2018.

UNESPAR - Universidade Estadual do Paraná. Campus de Curitiba II - FAP.

Bacharelado em Musicoterapia. Curitiba, c2019. Disponível em:

http://fap.curitiba2.unespar.edu.br/assuntos/graduacao/bacharelado-em-musicoterapia.

Acesso em: 12 out. 2019.

UNESPAR - Universidade Estadual do Paraná. Pró-Reitoria de Ensino de Graduação. Acesso, permanência e evasão. Paranavaí, 2017a. Disponível em:

http://prograd.unespar.edu.br/assuntos/acesso-permanencia-e-evasao. Acesso em: 28 set. 2018.

UNESPAR - Universidade Estadual do Paraná. Pró-Reitoria de Extensão e Cultura.

Diretoria de Assuntos Estudantis. Edital no 01/2017- Proec/DAE: Programa Institucional de Bolsas Permanência. Paranavaí, 24 abr. 2017b. Disponível em:

http://www.unespar.edu.br/noticias/programa-de-bolsa-permanencia-abre-inscricoescom-novidade/edital-01-2017-proec.pdf. Acesso em: 11 nov. 2018.

UNESPAR - Universidade Estadual do Paraná. Unespar mostra a verdade sobre o custo por aluno. Paranavaí, 12 fev. 2015. Disponível em:

http://www.unespar.edu.br/noticias/unespar-mostra-a-verdade-sobre-o-custo-por-aluno.

Acesso em: 12 nov. 2018.

Educ. Form., Fortaleza, v. 5, n. 3, e2080, set./dez. 2020

DOI: https://doi.org/10.25053/redufor.v5i15set/dez.2080

https://revistas.uece.br/index.php/redufor/index 
Sheila Maria Ogasavara Beggiato, Universidade Estadual do Paraná (Unespar), Programa de PósGraduação em Educação, Curso de Musicoterapia

ii@ https://orcid.org/0000-0002-5207-3362

Musicoterapeuta. Doutoranda em Educação pela Unespar, mestra em Educação pela Pontifícia Universidade Católica do Paraná (PUC-PR) e graduada em Musicoterapia pela Faculdade de Artes do Paraná, atual Unespar. Formação em Psicodrama Pedagógico pela Sociedade Paranaense de Psicodrama. Professora e supervisora do curso de bacharelado em Musicoterapia da Unespar Campus Curitiba II. Ex-editora-chefe da Revista Brasileira de Musicoterapia, vinculada à União Brasileira de Associações de Musicoterapia (UBAM). Membro e líder do grupo de pesquisa Núcleo de Estudos e Pesquisas Interdisciplinares em Musicoterapia (NEPIM), vinculado ao Conselho Nacional de Desenvolvimento Científico e Tecnológico (CNPq). Membro do Grupo de Pesquisa em Envelhecimento Humano (GPEH) da Unespar. Membro de comissão científica em diversos eventos científicos na área da musicoterapia e da música.

Contribuição de autoria: Orientou, construiu o questionário, analisou os resultados e discussão.

Lattes: http://lattes.cnpq.br/1731908722522643

E-mail: sheilabeggiato@gmail.com

Editor responsável: Alfrâncio Ferreira Dias Pareceristas ad hoc: Filipe Gracioli e Gustavo Araújo

\section{Como citar este artigo (ABNT):}

NASCIMENTO, Lázaro Castro Silva; BEGGIATO, Sheila Maria Ogasavara. Evasão escolar na graduação em Musicoterapia da Universidade Estadual do Paraná. Educ. Form., Fortaleza, v. 5, n. 3, p. 1-22, 2020. Disponível em: https://revistas.uece.br/index.php/redufor/article/view/2080. 


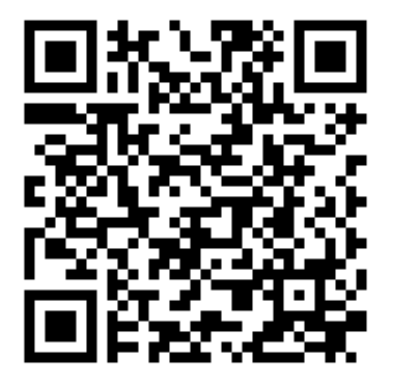

Recebido em 23 de outubro de 2019.

Aceito em 26 de março de 2020.

Publicado em 6 de julho de 2020. 